\title{
Laparoscopic liver resection: indications, limitations, and economic aspects
}

\author{
Moritz Schmelzle $^{1} \cdot$ Felix Krenzien $^{1} \cdot$ Wenzel Schöning ${ }^{1} \cdot$ Johann Pratschke $^{1}$
}

Received: 16 June 2020 / Accepted: 23 June 2020 / Published online: 1 July 2020

(C) The Author(s) 2020

\begin{abstract}
Background Minimally invasive techniques have increasingly found their way into liver surgery in recent years. A multitude of mostly retrospective analyses suggests several advantages of laparoscopic over open liver surgery. Due to the speed and variety of simultaneous technical and strategic developments, it is difficult to maintain an overview of the current status and perspectives in laparoscopic liver surgery.

Purpose This review highlights up-to-date aspects in laparoscopic liver surgery. We discuss established indications with regard to their development over time as well as continuing limitations of applied techniques. We give an assessment based on the current literature and according to our own center experiences, not least with regard to a highly topical cost discussion.

Conclusions While in the beginning mainly benign tumors were laparoscopically operated on, liver metastasis and hepatocellular carcinoma are now among the most frequent indications. Technical limitations remain and should be evaluated with the overall aim not to endanger quality standards in open surgery. Financial aspects cannot be neglected with the necessity of cost-covering reimbursement.
\end{abstract}

Keywords Laparoscopic liver surgery $\cdot$ Minimally invasive liver surgery $\cdot$ Robotic liver surgery

\section{Introduction}

Laparoscopic surgery of parenchymatous organs, e.g. liver and pancreas, has been developed relatively late, even though first reports of minimally invasive liver resections were back in the 1990s [1]. The development of laparoscopic liver surgery was accompanied by reservations and questions that have already been cleared or clarified years ago in other areas, such as colorectal surgery. However, as liver surgery differs significantly in many respects, it was not simply a matter of adopting answers from other fields, but of putting the feasibility and usefulness of the laparoscopic technique to the test again. The development has benefited from an early exchange between international pioneers in this field. The organization of consensus and guidelines meetings, e.g., 2008 in

Moritz Schmelzle

moritz.schmelzle@charite.de

1 Department of Surgery, Campus Charité Mitte and Campus Virchow-Klinikum, Charité - Universitätsmedizin, Corporate Member of Freie Universität Berlin, Humboldt-Universität zu Berlin, Augustenburger Platz 1, 13353 Berlin, Germany
Louisville, USA, 2014 in Morioka, Japan, 2018 in Southampton, UK, and later the founding of the International Laparoscopic Liver Society (ILLS), which organized first meetings in Paris in 2017 and Tokyo in 2019, were instrumental in the successful development of safe laparoscopic liver surgery [2-4].

Besides the pioneering spirit of some, its implementation was only made possible by technical innovations and strategic modifications of open surgery. While minimally invasive surgery has long been used equivalently for laparoscopic surgery, different techniques and strategies have emerged from autodidactic learning. Simultaneously, experience was gained in multiport, single-port, hand-assisted, and hybrid techniques, whereby country-specific preferences developed $[5,6]$. Intraoperative strategies, e.g., the caudal approach, and ideal techniques of parenchymal dissection were dominant topics in those days [7, 8]. Experiences with different entities, such as hepatocellular carcinoma (HCC) in cirrhosis, also varied greatly from country to country, depending on the local incidence and alternative treatment options, such as liver transplantation [9]. Since the first ILLS meeting in Paris in 2017, we have recently seen a homogenization of indications, applied techniques, and strategic approaches in laparoscopic liver surgery. 


\section{Indications}

\section{Benign liver tumors}

Symptomatic benign liver tumors (BLT), e.g. focal nodular hyperplasia, hemangioma, or hepatocellular adenoma, were the first to be resected laparoscopically back in the 1990s and early 2000s [10]. It became clear early on that the technique inherited certain advantages compared with the conventional open procedure. Overall morbidity, time to oral intake, and hospital stay were repeatedly shown to be reduced after laparoscopic liver surgery compared with the conventional open technique [11]. The relatively high rate of conversions to open surgery was not surprising as the management of intraoperative bleeding in particular was still a major challenge in those days [11]. All the more important for the successful implementation of this technique was the fact that there was no mortality in first multicentric reports [11]. It further simplified the implementation that no oncological concerns had to be eliminated with these resections in benign lesions. Meanwhile, retrospective studies with propensity score matching (PSM) and systematic reviews have proven the feasibility and safety of the minimally invasive technique for BLT, independent of the location, complexity, and resection extend [10-12]. Since prospective studies are probably not to be expected due to the rare indication alone, the laparoscopic technique can be defined as standard of care for BLT on the basis of the available data. Symptomatic growth is one of the indications for the resection of BLT and the question of whether the quality of life (QoL) can further be improved by the laparoscopic approach is another interesting aspect. In a recent review of 42 studies, eight studies used validated QoL tools. Of these eight studies, only two could show an advantage for laparoscopic over open surgery. Consequently, the superiority of the laparoscopic technique in terms of increasing QoL must be considered controversial, at least for BLT, and one must be careful in drawing any obvious conclusions [13].

\section{Colorectal liver metastasis}

After liver metastases could already be diagnosed laparoscopically in the 1960s, first reports of laparoscopic partial resections of superficially located and easily accessible colorectal liver metastases (CRLM) date back to the 1990s $[14,15]$. However, the time for a broad application of laparoscopic liver resections in CRLM has not yet come in the late 1990s since other questions remained unanswered, such as the reliable detection of occult liver metastases [16]. Consequently, the potential added value of minimally invasive techniques in CRLM was evaluated primarily with a view to improving staging and allowing appropriate selection of patients for resection, e.g. by diagnostic laparoscopy and laparoscopic ultrasonography [17]. Brice Gayet from Paris was one of the first to publish larger case series including laparoscopic major anatomical resections in CRLM in 2004 [18]. Even though conversion and complication rates were still comparatively high, acceptable oncological results were achieved in CRLM [18]. More than 10 years later, systematic reviews and meta-analysis including 4591 and 2259 patients, respectively, confirmed favorable short-term outcomes after laparoscopic liver surgery for CRLM with significantly reduced blood loss, lower operative transfusion requirement, shorter hospital stay, reduced overall morbidity, and reduced severe morbidity compared with conventional open surgery $[19,20]$. Regarding oncologic outcomes, there were no significant differences found between laparoscopic and open surgery, except for a higher $\mathrm{R} 0$ resection rate in the laparoscopic group. The latter rather confirmed the critics who attributed the convincing results to a selection in favor of laparoscopically operated cases. Thus, a randomized controlled trial (RCT) was urgently demanded. The first RCT (OSLO-COMET) comparing laparoscopic and open resections in CRLM was published 1 year later-in 2018 - by Fretland et al. [21]. Two hundred eighty patients were randomized, of whom 144 open and 129 laparoscopically operated patients were analyzed in the final evaluation. The results confirmed clear advantages for the laparoscopic procedure. Significant differences were found with regard to lower postoperative pain medication requirement, lower complication rate (Dindo-Clavien > II), lower comprehensive complication index, and shorter intensive care unit and hospital stay. In addition to the advantages already mentioned above, a subgroup analysis of the OSLO-COMET group using a standardized questionnaire revealed a higher QoL for patients after the resection of posterosuperior segments [22]. Long-term oncological results of this first RCT in laparoscopic liver surgery are still pending, but the results of previous meta-analyses and retrospective PSM analyses let anticipate favorable outcomes, at least a non-inferiority for the laparoscopic approach.

\section{Strategies in colorectal liver metastasis}

CRLM are often arranged multilocular and bilobar. Since they usually arise in normal liver parenchyma, except for chemotherapy-associated alterations, all strategic options must be considered when surgical treatment is planned [23]. Two-stage hepatectomy is a concept that has been established for more than 20 years with a large number of technical variants, which can help to address metastases initially classified as unresectable [24]. According to a French retrospective multicenter analysis of about 2500 patients with CRLM from 2015 , almost $20 \%$ of laparoscopically resected patients had bilobar lesions [25]. Portal vein embolization (PVE) as part of the concept was necessary in 13 of the 176 patients (7.4\%). The proportion of patients with extensive findings was lower 
than in the group of patients undergoing open surgery, clearly indicating a selection bias. Nevertheless, the authors concluded that patients who were considered suitable for laparoscopic liver resection appeared to benefit from the minimally invasive approach without impairing long-term survival. These results were confirmed in a recent study. Okumura et al. analyzed retrospective data from two experienced centers in Paris and confirmed laparoscopic two-stage hepatectomy in bilobar CRLM to be safe and associated with an improved outcome compared with open surgery [26]. In addition to established concepts such as PVE, hypertrophy of the left hepatic lobe can also be safely achieved by minimally invasive ALPPS (Associating Liver Partition with Portal vein ligation for Staged hepatectomy) with supposed advantages over the open technique [27]. Speaking from personal experience, ALPPS can be performed safely laparoscopically as well as roboticassisted, although equivalence must be confirmed by future comparative studies.

\section{Hepatocellular carcinoma and liver cirrhosis}

HCC is considered the most common indication for laparoscopic liver resection besides CRLM and results in HCC seem to confirm those in CRLM. First experiences in laparoscopic liver resections for HCC go back over 20 years as reported by Daniel Cherqui in a feasibility study in 30 patients [28]. Meanwhile there is one controlled randomized study ( $n=25$ vs. $n=25)$ comparing laparoscopic and open liver resection in early HCC $(<5 \mathrm{~cm})$ in compensated cirrhosis (CHILD A) from Egypt [29]. Operative time and hospital stay were decreased in the laparoscopic group with otherwise comparable perioperative results. The further course of the patients suggested that the oncological result was not affected by the laparoscopic procedure. Due to several limitations, this study must be evaluated with caution. Nevertheless, it should be mentioned that these results were supported by PSM analyses from Asia (Korea [30] ( $n=33$ vs. 33), China [31] ( $n=32$ vs. $32)$, Hong Kong [32] ( $n=110$ vs. 110)) and our group in Berlin [33] ( $n=56$ vs. 56). Repetitively, an advantage of the laparoscopic approach could be shown, especially with regard to a decrease of intra- and postoperative complications. Besides perioperative advantages, these analyses also confirmed a comparable oncological outcome with at least equivalent overall and recurrence-free survival. Although it has not yet been shown to be pathophysiologically conclusive, reduced trauma of the abdominal wall with less resulting pain and the preservation of collaterals seem to have a more significant beneficial influence than in liver healthy patients. As advantages can be witnessed especially in those with advanced cirrhosis (CHILD B), surgical indications may be extended in cirrhotic patients by advocating the minimally invasive approach even in unfavorable segments [34, 35]. It seems as if the underlying cirrhosis of the liver speaks clearly for and not against the minimally invasive technique, as initially postulated by some. This is supported by the 2018 EASL Clinical Practice Guidelines on the Management of Hepatocellular Carcinoma, according to which optimal surgical candidacy is based "on a multiparametric evaluation including compensated Child-Pugh class A liver function with MELD score $<10$, to be matched with grade of portal hypertension, acceptable amount of remaining parenchyma and possibility to adopt a laparoscopic/minimally invasive approach" [36].

\section{Intrahepatic cholangiocarcinoma}

First case reports in laparoscopic liver resections for intrahepatic cholangiocarcinoma (iCC) also go back 20 years [28, 37]. Harimoto et al. reported in 2002 on a left lateral sectionectomy with hilar lymphadenectomy (LAD) and recognized possible advantages of the minimally invasive technique in reduced blood loss and shortened hospital stay [37]. The low number of publications on minimally invasive liver resections in $\mathrm{iCC}$ in the following years was not only due to rarity of those tumors. In fact, the necessity of extended liver resections with/without biliary reconstruction and the complexity of hilar LAD have so far prevented a broad acceptance of laparoscopic techniques in iCC. Nevertheless, a recent systematic review of four retrospective observational studies including 204 patients with iCC basically confirmed results in CRLM and HCC [38]. Laparoscopic liver resection for iCC appears to provide short-term benefits without negatively affecting oncologic adequacy with regard to microscopically tumor-free margins and disease recurrence [38]. These results can be traced by means of a recent analysis from Berlin [39]. Clinical courses of all consecutive patients ( $n=159$ ) undergoing liver resection for iCC between January 2015 and October 2019 were reviewed, of which $23 \%$ of the interventions were performed minimally invasive [39]. After applying selection criteria, oncological short-term results after laparoscopic liver resection met oncological demands of open surgery with a R0 resection rate of $89 \%$ (74\% in open surgery) and a median number of eight retrieved lymph nodes ( $n=8$ in open surgery), latter complying with the AJCC staging manual (8th edition of American Joint Committee on Cancer) of 2017. A decreased overall morbidity (DindoClavien 1-5) of $30 \%$ in laparoscopic compared with $58 \%$ in open surgery translated in a shortened hospital stay of 8 days vs. 10 days, respectively. Obviously, our study should to be interpreted with caution due to the retrospective study design and high rate of excluded patients alone [39]. The majority of patients were apparently identified as unsuitable for the laparoscopic approach. Nevertheless, the study suggests that a selection of patients with iCC is reasonably possible and laparoscopic liver surgery in iCC should no longer represent a general contraindication. 


\section{Limitations}

\section{Difficulty scores indicate possible limitations}

There are multiple definitions and risk scores available to assess the difficulty of laparoscopic liver resections, of which the Iwate criteria are most commonly used [40-43]. Several parameters are included in the Iwate criteria, such as tumor location, tumor size, proximity of the tumor to large vessels, liver function, and technical considerations. All these aspects, alone or in combination, are usually not a contraindication per se, but can well be limiting with regard to the laparoscopic approach. Those criteria may help to define limitations individually depending on the findings and the personal as well as center-specific learning curves. Interestingly, not only the difficulty of a procedure can be assessed by the Iwate criteria from those preoperative variables but also postoperative complications [41]. This is of importance as possible limitations should be defined not only by technical restrictions but also by the rate of postoperative complications and the adherence on high (oncological) quality standards in open surgery.

\section{Abdominal adhesions and repeat liver resections}

Abdominal adhesions develop regularly after surgery and in particular after conventional open interventions. The extent of adhesions depends on the procedure and the postoperative course with significant interindividual differences in patients. Abdominal adhesiolysis can sometimes be technically complex and extensive adhesions often require adhesiolysis for several hours, even in the conventional open technique. According to a recent multicentric analysis of 2856 patients being scheduled for laparoscopic liver resection, previous open liver resection was found to be an independent predictor of intraoperative complications [44]. Indeed, extensive adhesions can be limiting for the laparoscopic approach, especially when evident in the upper abdomen, and the risk should be carefully weighed when choosing the technique. However, scars do not automatically indicate extensive adhesions. Even though assumptions are certainly slightly distorted by a preoperative patient selection, the rate of patients who cannot be operated laparoscopically due to prior open surgery is expected to be in the lower percentage range. As recently shown, almost half of our patients being scheduled for laparoscopic liver resection had a history of previous abdominal interventions [45]. Neither the postoperative complication rate nor the hospital stay was affected by abdominal adhesions in those patients. The above also applies to repeated liver resections, as recently shown for both CRLM and HCC [46, 47]. If repeated liver resection is considered possible laparoscopically, patients have common advantages over the open technique, e.g., less blood loss, a lower complication rate, and reduced hospital stay.

\section{Giant tumors}

As Shelat et al. could show, laparoscopic liver resection is feasible and safe for large malignant tumors and can be performed with an acceptable morbidity and oncologic efficiency [48]. However, the subgroup analysis of "giant" malignant tumors indicated that LLR is associated with greater blood loss and a longer operative time. Accordingly, the size of the tumor is also taken into account in the Iwate criteria, so that tumors larger than $3 \mathrm{~cm}$ are classified with an increase in difficulty [40]. Giant tumors in particular are extremely demanding to operate on, where limits of what is considered technically feasible can easily be reached. The placement of trocars, the mobilization of a liver lobe, and the accidental tumor perforation by shear forces are examples of possible intraoperative difficulties. Further arguments against the laparoscopic procedure for giant tumors include that conventional recovery bags are too small and a comparatively long incision is required to retrieve the specimen. In this respect, the question of feasibility depends primarily on whether the resection can be performed safely and within a reasonable time. Of note, if technically feasible, well-known advantages of minimally invasive surgery have also been confirmed in the literature for giant tumors [49]. Therefore, the decision whether to operate laparoscopically or rather conventionally open should be based on the findings and, again, on the own learning curve and personal experiences made.

\section{Multiple bilobar liver metastases}

Besides giant tumors, the role of laparoscopic liver surgery is also controversial in case of multiple bilobar metastasis. As mentioned above, according to a recent French study, twostage hepatectomy in bilobar CRLM is obviously safe and associated with an improved outcome compared with open surgery [26]. As Okumura et al. reported, number and maximum diameter of lesions at first stage ranged from 1 to 5 and 3 to $40 \mathrm{~mm}$ after propensity score matching, respectively [26]. Of note, microscopically tumor-free margins could be achieved in 96\% [26]. These data are indeed convincing and speak for the long experience of these centers in complex laparoscopic liver surgery. Without any question, a broad experience in sonography-guided parenchymal dissection is indispensable [50]. 3D laparoscopy, as is standard practice at the Hôpital Pitié-Salpêtrière in Paris, should be mentioned as an another example for important supportive visual techniques. Use of indocyanine green (ICG), being widely used in Japan and experienced centers elsewhere, can further help to both detect superficial lesions and guide difficult parenchymal dissection [51]. Research is being conducted on the application of virtual realities, what could also be beneficial in this context $[52,53]$. Nevertheless, multiple partial resections of (superficial) liver metastases remain technically demanding 
without all these aids and extremely time-consuming, e.g., in case of multiple vanishing lesions after chemotherapy. In this respect, one must also make a good estimate of which efforts are really useful in everyday clinical practice.

\section{Resection of posterosuperior segments}

The standard positioning of the optic trocar provides a view from caudal to cranial. In this regard, the so-called caudal approach has proven itself in several laparoscopic resections, e.g., right or left hepatectomy [54]. As much as this strategy may be useful for caudocranial parenchymal dissection, it is of little use for the resection of posterosuperior segments. Especially the anatomical resection of segments 7 and 8 (dorsal) can well be borderline feasible due to a poor overview and unfavorable working angles. In recent years, approaches have been adapted exemplified by the appropriate positioning of the patient and the intercostal placement of trocars [55]. Further, dissection strategies have been refined, e.g., Diamond technique, allowing safe laparoscopic parenchymal-sparing liver resections of lesions in posterosuperior segments, even in cirrhosis [56, 57]. Nevertheless, these interventions often represent limitations and should be reserved for most experienced laparoscopic liver surgeons, who can safely master possible complications such as (venous) bleeding, e.g., from the right hepatic vein [58]. It is not for nothing that resection of segments 7 and 8 is rated with a maximum score of 5 in the Iwate criteria [40]. The overall goal must always be a safe resection that fulfills high oncological quality criteria of open surgery. Compromises in favor of the laparoscopic technique should be viewed critically and early conversion in case of suboptimal settings, e.g., to hand-assisted or hybrid liver resection, should be preferred.

\section{Hilar lymphadenectomy}

As recently reported, fully laparoscopic dissection of hilar lymph nodes is considered technically possible and seems safe in experienced hands $[39,59]$. This is noteworthy as technical limitations in hilar LAD were thought to be a contraindication to laparoscopic surgery for iCC in the past. General expectations were dampened by first reports and doubts regarding the oncological equivalence of the minimally invasive procedure arose. The median number of retrieved lymph nodes often did not correspond to current recommendations for iCC $[38,60]$. Moreover, cases of laparoscopically operated iCC in which no LAD was performed at all were disturbing $[38,60]$. In a US national cancer database analysis of 2309 patients with iCC, the percentage of nodal evaluation was significantly lower in patients undergoing laparoscopic liver resection (39\%) compared with patients being scheduled for open surgery $(61 \%)$ [61]. Given an overall nodal evaluation of $58 \%$, the experience of reporting centers seems particularly important, not only in laparoscopic surgery [61]. Therefore, the discussion about possible limits of LAD is very well suited to describe the further development of laparoscopic (and open) liver surgery in the coming years in general. We will likely see a development towards a broad application of laparoscopic surgery for technically less demanding liver lesions with highly specialized applications, such as extended hepatectomy with LAD, being reserved for a few centers with the appropriate experience. To accompany this twin-track development, strict quality control is required to ensure equivalence to the conventional open technique. A first step in this direction would be to include hilar LAD in revised risk scores in the future.

\section{Biliary reconstruction}

According to a current publication from Germany, mortality after liver resection increases depending on the extent and need for biliary reconstruction up to $25 \%$ [62]. Trisectionectomy with hepaticojejunostomy is a timeconsuming and technically most demanding intervention even in the conventional open technique. Possibilities of reconstructing small bile ducts to jejunum are clearly limited in the laparoscopic technique that, apart from the quality achieved, would likely further extend the operating time. The question arises whether open surgery should be reserved for these particularly complex interventions. In retrospect, there were many technical boundaries that were torn down one after the other. Therefore, it is not surprising that in the meantime, there are first case series of minimally invasive surgery for perihilar cholangiocarcinoma (PHC) [63-65]. Evidence has been provided that both extended hepatectomy as well as biliary reconstruction should be considered technically possible. However, these reports are not sufficient for a robust assessment. Experience with PHC is up to now limited to individual cases and small case series from highly experienced centers $[63,65,66]$. Larger series or ideally comparative studies are not to be expected in the near future due to the rarity of these interventions alone. Improvements to technical possibilities, e.g., a simplification of sewing, are needed to sufficiently overcome this last hurdle. Robotic-assisted liver surgery is still in its infancy and first experience does not yet allow a final evaluation. From our personal experience, however, first reports can be traced after the robotic technique could possibly have advantages in sewing and thus biliary reconstruction $[67,68]$.

\section{Living donor liver transplantation}

Repeatedly shown perioperative advantages of the laparoscopic technique, e.g., reduced blood loss and lower complication rates, seem particularly attractive in healthy individuals 
as for both pediatric and adult living donor liver transplantation (LDLT). Indeed, there are an increasing number of studies suggesting favorable postoperative outcomes after laparoscopic donor hepatectomy for LDLT. Especially laparoscopic left lateral sectionectomy is meanwhile a standard procedure in specialized units yielding expected advantages in the donor with comparable short and long-term outcome to open surgery in the recipient [69-71]. However, a learning curve of 25 fully laparoscopic living donor left lateral sectionectomies under proctorship for an expert liver transplantation surgeon was recently suggested, which indicates that safe introduction of laparoscopic minor liver resections is restricted to high volume LDLT centers [72]. The significance of major liver resection in LDLT has not yet been conclusively clarified [73]. Results from a recent series of 412 minimally invasive donor hepatectomies being performed at 10 leading centers were comparable with those of benchmarking series of open standard donor hepatectomy with a morbidity below 10\% (DindoClavien 3-4) and no mortality [74]. A retrospective analysis of 123 pure laparoscopic donor right hepatectomies (PLDRH) confirmed similar complication rates to the open technique [75]. However, there was a trend towards more biliary complications (leak and stricture) compared with the open technique ( $n=123)$ after propensity score matching. This underlines the importance of a previous study reporting on a higher percentage of multiple bile duct openings in PLDRH [76]. With regard to the course of the recipient, it seems noteworthy that time to remove the liver and warm ischemic time are usually longer after PLDRH compared with open right hepatectomy [77]. This is clinically significant because the longer ischemic time must be blamed, at least in parts, for the higher rate of biliary complications after PLDRH [77]. A final evaluation of this technique is not yet possible based on the available data and PLDRH remains controversial due to safety concerns both in the donor and in the recipient. More experience needs to be gathered especially on long-term outcomes and with regard to biliary complications.

\section{Hybrid and hand-assisted techniques}

The use of hybrid and hand-assisted techniques (HALS) leads to a decrease in complexity in the Iwate criteria [40]. This is of importance as individual technical limits can easily be shifted by using these techniques. Especially in the learning curve hybrid and HALS can be useful and allow complex resections that would otherwise be hardly possible at this stage [78]. In a recent Italian series of PHC, biliary reconstruction after extended hepatectomy using hybrid techniques completed a previously fully laparoscopic resection [64]. Even though the insertion of a handport may be associated with an increased incidence of hernias in the long term, the postoperative outcome does not seem to be negatively affected, when compared with fully laparoscopic surgery $[78,79]$. From a personal perspective, the liberal combination of different techniques will be trend-setting rather than the compulsive desire to adhere to fully laparoscopic surgery. This will also apply to robotic-assisted surgery, which will complement rather than replace established minimally invasive techniques, striving to expand indications while maintaining oncological principles and to reduce complications [80].

\section{Economic aspects}

With regard to economic aspects, the comparison of laparoscopic and open liver surgery is particularly difficult. One must distinguish precisely between minor and major liver resections, intraoperative and postoperative costs, and countryspecific reimbursement systems. One has to weigh up classical cost drivers, such as postoperative complications, against new ones in laparoscopic surgery, such as expensive stapler cartridges. A distinction must also be made between real and virtual costs, e.g., for human resources, and these must be constantly evaluated in the light of modified reimbursement systems.

\section{Intraoperative costs}

In a retrospective analysis, our group compared costs in laparoscopic and open hemihepatectomy being allocated to the DRG (diagnosis-related group) H01A (complex operations of the liver and pancreas with complex intensive care treatment) or H01B (operations of the liver and pancreas without complex intensive care treatment) [81]. After propensity score matching, intraoperative costs were significantly higher in laparoscopic compared with open hemihepatectomy with $8000 €$ and $\sim 4000 €$, respectively. In fact, the difference in intraoperative costs between both groups was mainly due to the laparoscopic instruments with $73 \%$ and a longer operation time with $27 \%$. Higher total intraoperative costs were confirmed by a retrospective analysis from UK [82] and USA [83] and the prospective OSLO-COMET trial from Norway [21]. Whereas consumables/disposable equipment were considered the main cost driver in minor resections, costs for staff and theater time are obviously gaining in importance in laparoscopic major hepatectomy [21, 82]. Importantly, intraoperative costs can possibly even be reduced in minor resections by a shorter operation time when compared with open surgery [82].

\section{Important intraoperative cost drivers}

The extended operating time is a decisive disadvantage of the laparoscopic technique in terms of cost-effectiveness. However, it should not be forgotten that the data generated so far have been collected within the framework of learning 
curves and an improvement in this respect is expected in the coming years at many centers $[84,85]$. Staplers are commonly used in laparoscopic liver surgery for transection of parenchyma and vessels; however, they are among the major cost drivers in laparoscopic surgery $[81,86,87]$. Therefore, econometric aspects should not be disregarded when selecting intraoperative strategies and favored techniques. Anyways, prices of laparoscopic devices will likely decrease in the future due to the increasing demand. Increasing competition from manufacturers and expiring patent rights will create further cost pressure, so that these aspects will fade into the background.

\section{Postoperative and total costs}

Liver resection in general is still associated with a high incidence of complications that lead to a considerable financial burden. Therefore, low complication rates of laparoscopic liver surgery may be favorable for billing [88]. In our analysis, patients after laparoscopic hemihepatectomy were indeed characterized by a significantly lower rate of postoperative complications and a shortened median hospital stay of 5 days [81], resulting in comparable total costs after laparoscopic and open hemihepatectomy with $17,369.85 €$ and $16,103.64 €$, respectively. Cost-effectiveness was confirmed by the OSLOCOMET trial due to shorter stays on ICU and hospital stay and a lower readmission rate [21]. Abu Hilal et al. from UK showed that the lower postoperative costs for both major and minor procedures are mainly due to cost reduction on ICU, wards, bloods and X-ray [82]. This resulted in same total costs in major hepatectomy and even lower total costs after left lateral sectionectomy. Cost-effectiveness of laparoscopic resections obviously varies with the complexity of the procedure. Higher intraoperative costs, e.g., for surgical equipment or due to longer operating times, can obviously be recouped by a smaller deviation from the normal postoperative course, with advantages noted especially for laparoscopic minor resections.

\section{Comparability of different centers}

Costs can be easily calculated as shown above; however, different currencies (e.g., USD and Euro) and reimbursement systems make an international comparison hardly possible. Not even the one-off cost analysis of single centers may provide a profound basis for the upcoming years. Due to constantly changing costs and modifications in reimbursement systems, a constant update of the calculation is necessary. The surgeon is thus jointly responsible for ensuring that this new technique is not withheld from patients due to financial considerations. In addition, more work will be needed in the future to adapt the reimbursement for the laparoscopic technique accordingly. The country of Japan should be noted in this regard as insurance reimbursements are guaranteed for all types of laparoscopic liver surgery (without vascular and biliary reconstruction); likewise, the insurance companies demanded a mandatory registry database. The number of LLRs has increased remarkably in Japan since the introduction of this special refund [89].

\section{Costs in robotic-assisted liver surgery}

In a recent study from the USA, overall benefits of minimally invasive liver surgery could be confirmed for robotic-assisted liver resection $(n=68)$ with fewer complications, shorter ICU, and hospital stay compared with open liver resection $(n=55)$ [90]. This resulted in comparable average total costs with $\$ 37,518$ for robotic surgery and $\$ 41,948$ for open technique. The cost-effectiveness of robot-assisted liver resection compared with conventional laparoscopic liver resection, however, has hardly been investigated so far. Should robotic-assisted surgery find its way into liver surgery in the long term, it will be necessary to discuss costs and reimbursement at an early stage. In particular, it must be clarified in this context which interventions should be performed laparoscopically and which robotic-assisted. It also remains interesting to see how the costs develop after new providers have entered the market.

\section{Summary}

In recent years, liver surgery has been increasingly integrated into multimodal therapeutic strategies. In this respect, the focus has been on the safety of surgical interventions and low complication rates. These growing quality demands have paved the way for gentle, minimally invasive techniques into complex liver surgery. There are now a large number of mostly retrospective studies that have repeatedly confirmed intra- and postoperative advantages over conventional open liver surgery. Initial fears that this would have to be weighed against the oncological disadvantages of minimally invasive techniques were not confirmed based on existing studies. In this respect, it is currently necessary to evaluate different minimally invasive techniques with regard to their advantages and possible weaknesses.

CRLM and HCC in cirrhosis have proven to be particularly suitable for laparoscopic approaches, and initial prospective studies have now confirmed this for these entities. While CRLM and HCC together account for more than half of the indications at most centers, minimally invasive surgery of CCA is still limited to a small number of centers with very high expertise. Limitations in general and in CCA in particular often result from the complexity of interventions, some of which can be estimated by means of established complexity scores. However, compromises with regard to intraoperative safety and the adherence to oncological principles need to be considered inacceptable. In this respect, the risk of a laparoscopic resection must always be assessed on the basis of the surgeon's own learning curve and individually weighed against the 
potential benefit for the patient. As some limitations of minimally invasive techniques will likely remain in the foreseeable future, open surgery can only be supplemented but not replaced.

Despite all optimism in this field, economic considerations in laparoscopic and robotic-assisted liver surgery cannot be ignored. Laparoscopic liver surgery is generally associated with an increased cost for intraoperative consumables and, at least in the learning curve, longer operating times. As higher intraoperative costs are offset by lower postoperative costs, comparable total costs often result. A holistic understanding of costs and charges in laparoscopic and open liver surgery seems particularly important in discussions with hospital administration. With regard to minimally invasive and especially robotic-assisted liver surgery, it therefore seems essential to describe the advantages and substantiate them as thoroughly as possible. The necessity of costcovering accounting must also be made clear, analogous to lived realities in Japan. Since there is no culture of negative reporting in the field of surgery, it seems reasonable to adopt efforts for quality control from countries like Japan with the introduction of mandatory nationwide registries.

Authors' contributions MS, FK, WS, and JP participated in the study conception and design, drafting of the article, and critical revision.

Funding Information Open Access funding provided by Projekt DEAL.

\section{Compliance with ethical standards}

Conflict of interest The authors declare the following conflicts of interest:

Moritz Schmelzle - Merck, Bayer, Erbe, Ethicon, Takeda, Olympus, Medtronic, Intuitive.

Wenzel Schöning-Merck, Bayer, Ethicon.

Johann Pratschke-Merck, Medtronic, Intuitive, Verb Surgical.

Ethical approval This article does not contain any studies with human participants or animals performed by any of the authors.

Open Access This article is licensed under a Creative Commons Attribution 4.0 International License, which permits use, sharing, adaptation, distribution and reproduction in any medium or format, as long as you give appropriate credit to the original author(s) and the source, provide a link to the Creative Commons licence, and indicate if changes were made. The images or other third party material in this article are included in the article's Creative Commons licence, unless indicated otherwise in a credit line to the material. If material is not included in the article's Creative Commons licence and your intended use is not permitted by statutory regulation or exceeds the permitted use, you will need to obtain permission directly from the copyright holder. To view a copy of this licence, visit http://creativecommons.org/licenses/by/4.0/.

\section{References}

1. Kaneko H, Takagi S, Shiba T (1996) Laparoscopic partial hepatectomy and left lateral segmentectomy: technique and results of a clinical series. Surgery. 120:468-475
2. Buell JF, Cherqui D, Geller DA, O'Rourke N, Iannitti D, Dagher I et al (2009) The international position on laparoscopic liver surgery: the Louisville statement, 2008. Ann Surg 250:825-830

3. Wakabayashi G, Cherqui D, Geller DA, Buell JF, Kaneko H, Han HS, Asbun H, O Rourke N, Tanabe M, Koffron AJ, Tsung A, Soubrane O, Machado MA, Gayet B, Troisi RI, Pessaux P, van Dam R, Scatton O, Abu Hilal M, Belli G, Kwon CH, Edwin B, Choi GH, Aldrighetti LA, Cai X, Cleary S, Chen KH, Schön MR, Sugioka A, Tang CN, Herman P, Pekolj J, Chen XP, Dagher I, Jarnagin W, Yamamoto M, Strong R, Jagannath P, Lo CM, Clavien PA, Kokudo N, Barkun J, Strasberg SM (2015) Recommendations for laparoscopic liver resection: a report from the second international consensus conference held in Morioka. Ann Surg 261:619-629

4. Abu Hilal M, Aldrighetti L, Dagher I, Edwin B, Troisi RI, Alikhanov R, Aroori S, Belli G, Besselink M, Briceno J, Gayet B, D'Hondt M, Lesurtel M, Menon K, Lodge P, Rotellar F, Santoyo J, Scatton O, Soubrane O, Sutcliffe R, van Dam R, White S, Halls MC, Cipriani F, van der Poel M, Ciria R, Barkhatov L, Gomez-Luque Y, Ocana-Garcia S, Cook A, Buell J, Clavien PA, Dervenis C, Fusai G, Geller D, Lang H, Primrose J, Taylor M, van Gulik T, Wakabayashi G, Asbun H, Cherqui D (2018) The Southampton consensus guidelines for laparoscopic liver surgery: from indication to implementation. Ann Surg 268: $11-18$

5. Lin N-C, Nitta H, Wakabayashi G (2013) Laparoscopic major hepatectomy: a systematic literature review and comparison of 3 techniques. Ann Surg 257:205-213

6. Benzing C, Krenzien F, Atanasov G, Seehofer D, Sucher R, Zorron $\mathrm{R}$ et al (2015) Single incision laparoscopic liver resection (SILL)-a systematic review. GMS Interdiscip Plast Reconstr Surg DGPW 4: Doc17

7. Buell JF, Gayet B, Han H-S, Wakabayashi G, Kim K-H, Belli G, Cannon R, Saggi B, Keneko H, Koffron A, Brock G, Dagher I (2013) Evaluation of stapler hepatectomy during a laparoscopic liver resection. HPB. 15:845-850

8. Scatton O, Brustia R, Belli G, Pekolj J, Wakabayashi G, Gayet B (2015) What kind of energy devices should be used for laparoscopic liver resection? Recommendations from a systematic review. J Hepatobiliary Pancreat Sci 22:327-334

9. Zhou Y-M, Shao W-Y, Zhao Y-F, Xu D-H, Li B (2011) Metaanalysis of laparoscopic versus open resection for hepatocellular carcinoma. Dig Dis Sci 56:1937-1943

10. Descottes B, Glineur D, Lachachi F, Valleix D, Paineau J, Hamy A, Morino M, Bismuth H, Castaing D, Savier E, Honore P, Detry O, Legrand M, Azagra JS, Goergen M, Ceuterick M, Marescaux J, Mutter D, Hemptinne B, Troisi R, Weerts J, Dallemagne B, Jehaes C, Gelin M, Donckier V, Aerts R, Topal B, Bertrand C, Mansvelt B, Krunckelsven L, Herman D, Kint M, Totte E, Schockmel R, Gigot JF (2003) Laparoscopic liver resection of benign liver tumors. Surg Endosc 17:23-30

11. Troisi R, Montalti R, Smeets P, Van Huysse J, Van Vlierberghe H, Colle I et al (2008) The value of laparoscopic liver surgery for solid benign hepatic tumors. Surg Endosc 22:38-44

12. Wabitsch S, Kästner A, Haber PK, Benzing C, Krenzien F, Andreou A, Kamali C, Lenz K, Pratschke J, Schmelzle M (2019) Laparoscopic versus open liver resection for benign tumors and lesions: a case matched study with propensity score matching. J Laparoendosc Adv Surg Tech A 29:15181525

13. van Rosmalen BV, de Graeff JJ, van der Poel MJ, de Man IE, Besselink M, Abu Hilal M, Busch OR, Verheij J, van Gulik TM (2019) Impact of open and minimally invasive resection of symptomatic solid benign liver tumours on symptoms and quality of life: a systematic review. HPB. 21:1119-1130 
14. Henning H, Meyer-Burg J, Häring R (1967) Liver metastases of an appendiceal carcinoid discovered through laparoscopy. Med Klin 62:1464-1465

15. Wayand W, Woisetschläger R (1993) Laparoscopic resection of liver metastasis. Chirurg. 64:195-197

16. Jarnagin WR, Fong Y, Ky A, Schwartz LH, Paty PB, Cohen AM, Blumgart LH (1999) Liver resection for metastatic colorectal cancer: assessing the risk of occult irresectable disease. J Am Coll Surg 188:33-42

17. Rahusen FD, Cuesta MA, Borgstein PJ, Bleichrodt RP, Barkhof F, Doesburg T, Meijer S (1999) Selection of patients for resection of colorectal metastases to the liver using diagnostic laparoscopy and laparoscopic ultrasonography. Ann Surg 230:31-37

18. Vibert E, Kouider A, Gayet B (2004) Laparoscopic anatomic liver resection. HPB. 6:222-229

19. Zhang X-L, Liu R-F, Zhang D, Zhang Y-S, Wang T (2017) Laparoscopic versus open liver resection for colorectal liver metastases: a systematic review and meta-analysis of studies with propensity score-based analysis. Int J Surg 44:191-203

20. Cheng Y, Zhang L, Li H, Wang L, Huang Y, Wu L, Zhang Y (2017) Laparoscopic versus open liver resection for colorectal liver metastases: a systematic review. J Surg Res 220:234-246

21. Fretland Å, Dagenborg VJ, Bjørnelv GMW, Kazaryan AM, Kristiansen R, Fagerland MW, Hausken J, Tønnessen TI, Abildgaard A, Barkhatov L, Yaqub S, Røsok BI, Bjørnbeth BA, Andersen MH, Flatmark K, Aas E, Edwin B (2018) Laparoscopic versus open resection for colorectal liver metastases: the OSLOCOMET randomized controlled trial. Ann Surg 267:199-207

22. Aghayan DL, Fretland ÅA, Kazaryan AM, Sahakyan MA, Dagenborg VJ, Bjørnbeth BA, Flatmark K, Kristiansen R, Edwin B (2019) Laparoscopic versus open liver resection in the posterosuperior segments: a sub-group analysis from the OSLOCOMET randomized controlled trial. HPB. 21:1485-1490

23. Duwe G, Knitter S, Pesthy S, Beierle AS, Bahra M, Schmelzle M, Schmuck RB, Lohneis P, Raschzok N, Öllinger R, Sinn M, Struecker B, Sauer IM, Pratschke J, Andreou A (2017 Sep) Hepatotoxicity following systemic therapy for colorectal liver metastases and the impact of chemotherapy-associated liver injury on outcomes after curative liver resection. Eur J Surg Oncol 43(9): $1668-1681$

24. Adam R, Laurent A, Azoulay D, Castaing D, Bismuth H (2000) Two-stage hepatectomy: a planned strategy to treat irresectable liver tumors. Ann Surg 232:777-785

25. Allard M-A, Cunha AS, Gayet B, Adam R, Goere D, Bachellier P, Azoulay D, Ayav A, Navarro F, Pessaux P, Colorectal Liver Metastases-French Study Group (2015) Early and long-term oncological outcomes after laparoscopic resection for colorectal liver metastases: a propensity score-based analysis. Ann Surg 262:794802

26. Okumura S, Goumard C, Gayet B, Fuks D, Scatton O (2019) Laparoscopic versus open two-stage hepatectomy for bilobar colorectal liver metastases: a bi-institutional, propensity score-matched study. Surgery. 166:959-966

27. Michal K, Sau M, Tamara GMH, Long JR (2020) A better route to ALPPS: minimally invasive vs open ALPPS. Surg Endosc 34: 2379-2389

28. Cherqui D, Husson E, Hammoud R, Malassagne B, Stéphan F, Bensaid S, Rotman N, Fagniez PL (2000) Laparoscopic liver resections: a feasibility study in 30 patients. Ann Surg 232:753-762

29. El-Gendi A, El-Shafei M, El-Gendi S, Shawky A (2018) Laparoscopic versus open hepatic resection for solitary hepatocellular carcinoma less than $5 \mathrm{~cm}$ in cirrhotic patients: a randomized controlled study. J Laparoendosc Adv Surg Tech A. 28(3):302310

30. Yoon Y-I, Kim K-H, Kang S-H, Kim W-J, Shin M-H, Lee S-K, Jung DH, Park GC, Ahn CS, Moon DB, Ha TY, Song GW, Hwang
S, Lee SG (2017) Pure laparoscopic versus open right hepatectomy for hepatocellular carcinoma in patients with cirrhosis: a propensity score matched analysis. Ann Surg 265:856-863

31. Xu H-W, Liu F, Li H-Y, Wei Y-G, Li B (2018) Outcomes following laparoscopic versus open major hepatectomy for hepatocellular carcinoma in patients with cirrhosis: a propensity score-matched analysis. Surg Endosc 32:712-719

32. Cheung TT, Dai WC, Tsang SHY, Chan ACY, Chok KSH, Chan SC, Lo CM (2016) Pure laparoscopic hepatectomy versus open hepatectomy for hepatocellular carcinoma in 110 patients with liver cirrhosis: a propensity analysis at a single center. Ann Surg 264: 612-620

33. Andreou A, Struecker B, Raschzok N, Krenzien F, Haber P, Wabitsch S, Waldbaur C, Touet EM, Eichelberg AC, Atanasov G, Biebl M, Bahra M, Öllinger R, Schmelzle M, Pratschke J (2018) Minimal-invasive versus open hepatectomy for hepatocellular carcinoma: comparison of postoperative outcomes and longterm survivals using propensity score matching analysis. Surg Oncol 27:751-758

34. Cipriani F, Fantini C, Ratti F, Lauro R, Tranchart H, Halls M, Scuderi V, Barkhatov L, Edwin B, Troisi RI, Dagher I, Reggiani P, Belli G, Aldrighetti L, Abu Hilal M (2018) Laparoscopic liver resections for hepatocellular carcinoma. Can we extend the surgical indication in cirrhotic patients? Surg Endosc 32:617-626

35. Levi Sandri GB, Ettorre GM, Aldrighetti L, Cillo U, Dalla Valle R, Guglielmi A et al (2019) Laparoscopic liver resection of hepatocellular carcinoma located in unfavorable segments: a propensity score-matched analysis from the I Go MILS (Italian Group of Minimally Invasive Liver Surgery) Registry. Surg Endosc 33: $1451-1458$

36. European Association for the Study of the Liver (2018) EASL clinical practice guidelines: management of hepatocellular carcinoma. J Hepatol 69(1):182-236

37. Harimoto N, Shimada M, Tsujita E, Maehara S, Rikimaru T, Yamashita Y, Maeda T, Tanaka S, Shirabe K, Sugimachi K (2002) Laparoscopic hepatectomy and dissection of lymph nodes for intrahepatic cholangiocarcinoma. Case report Surg Endosc 16(12): 1806

38. Guerrini GP, Esposito G, Tarantino G, Serra V, Olivieri T, Catellani B, Assirati G, Guidetti C, Ballarin R, Magistri P, di Benedetto F (2020) Laparoscopic versus open liver resection for intrahepatic cholangiocarcinoma: the first meta-analysis. Langenbeck's Arch Surg 405:265-275

39. Haber PK, Wabitsch S, Kästner A, Andreou A, Krenzien F, Schöning W, Pratschke J, Schmelzle M (2020) Laparoscopic liver resection for intrahepatic cholangiocarcinoma: a single-center experience. J Laparoendosc Adv Surg Tech A.

40. Wakabayashi G (2016) What has changed after the Morioka consensus conference 2014 on laparoscopic liver resection? Hepatobiliary Surg Nutr 5:281-289

41. Krenzien F, Wabitsch S, Haber P, Kamali C, Brunnbauer P, Benzing C, Atanasov G, Wakabayashi G, Öllinger R, Pratschke J, Schmelzle M (2018) Validity of the Iwate criteria for patients with hepatocellular carcinoma undergoing minimally invasive liver resection. J Hepatobiliary Pancreat Sci. 25:403-411

42. Okamura Y, Yamamoto Y, Sugiura T, Ito T, Ashida R, Ohgi K, Uesaka K (2019) Novel patient risk factors and validation of a difficulty scoring system in laparoscopic repeat hepatectomy. Sci Rep 9:17653

43. Hallet J, Pessaux P, Beyfuss KA, Jayaraman S, Serrano PE, Martel G, Coburn NG, Piardi T, Mahar AL (2019) Critical appraisal of predictive tools to assess the difficulty of laparoscopic liver resection: a systematic review. Surg Endosc 33:366-376

44. Halls MC, Berardi G, Cipriani F, Barkhatov L, Lainas P, Harris S, D'Hondt M, Rotellar F, Dagher I, Aldrighetti L, Troisi RI, Edwin B, Abu Hilal M (2018) Development and validation of a difficulty 
score to predict intraoperative complications during laparoscopic liver resection. Br J Surg 105:1182-1191

45. Feldbrügge L, Wabitsch S, Benzing C, Krenzien F, Kästner A, Haber PK et al (2019) Safety and feasibility of laparoscopic liver resection in patients with a history of abdominal surgeries. HPB

46. van der Poel MJ, Barkhatov L, Fuks D, Berardi G, Cipriani F, Aljaiuossi A, Lainas P, Dagher I, D'Hondt M, Rotellar F, Besselink MG, Aldrighetti L, Troisi RI, Gayet B, Edwin B, Abu Hilal M (2019) Multicentre propensity score-matched study of laparoscopic versus open repeat liver resection for colorectal liver metastases. Br J Surg 106:783-789

47. Liang Y, Lin C, Zhang B, Cao J, Chen M, Shen J, Feng X, Xiao G, Pan L, Chen K, Maher H, Cai X (2020) Perioperative outcomes comparing laparoscopic with open repeat liver resection for posthepatectomy recurrent liver cancer: a systematic review and metaanalysis. Int J Surg 79:17-28

48. Shelat VG, Cipriani F, Basseres T, Armstrong TH, Takhar AS, Pearce NW, AbuHilal M (2015) Pure laparoscopic liver resection for large malignant tumors: does size matter? Ann Surg Oncol 22: $1288-1293$

49. Hu M, Chen K, Zhang X, Li C, Song D, Liu R (2020) Robotic, laparoscopic or open hemihepatectomy for giant liver haemangiomas over $10 \mathrm{~cm}$ in diameter. BMC Surg 20:93

50. Ellebaek SB, Fristrup CW, Hovendal C, Qvist N, Bundgaard L, Salomon S, Støvring J, Mortensen MB (2017) Randomized clinical trial of laparoscopic ultrasonography before laparoscopic colorectal cancer resection. Br J Surg 104:1462-1469

51. Kose E, Kahramangil B, Aydin H, Donmez M, Takahashi H, Acevedo-Moreno L-A, et al. A comparison of indocyanine green fluorescence and laparoscopic ultrasound for detection of liver tumors. HPB. 2019

52. Prevost GA, Eigl B, Paolucci I, Rudolph T, Peterhans M, Weber S, Beldi G, Candinas D, Lachenmayer A (2019) Efficiency, accuracy and clinical applicability of a new image-guided surgery system in 3D laparoscopic liver surgery. J Gastrointest Surg

53. Sauer IM, Queisner M, Tang P, Moosburner S, Hoepfner O, Horner R, Lohmann R, Pratschke J (2017) Mixed reality in visceral surgery: development of a suitable workflow and evaluation of intraoperative use-cases. Ann Surg 266:706-712

54. Yoh T, Cauchy F, Kawai T, Schneck A-S, Le Roy B, Goumard C et al (2020) Laparoscopic right hepatectomy using the caudal approach is superior to open right hepatectomy with anterior approach and liver hanging maneuver: a comparison of short-term outcomes. Surg Endosc 34:636-645

55. Inoue Y, Suzuki Y, Fujii K, Kawaguchi N, Ishii M, Masubuchi S, Yamamoto M, Hirokawa F, Hayashi M, Uchiyama K (2017) Laparoscopic liver resection using the lateral approach from intercostal ports in segments VI, VII, and VIII. J Gastrointest Surg 21: 2135-2143

56. Haber PK, Wabitsch S, Krenzien F, Benzing C, Andreou A, Schöning W, Öllinger R, Pratschke J, Schmelzle M (2019) Laparoscopic liver surgery in cirrhosis-addressing lesions in posterosuperior segments. Surg Oncol 28:140-144

57. Cipriani F, Shelat VG, Rawashdeh M, Francone E, Aldrighetti L, Takhar A, Armstrong T, Pearce NW, Abu Hilal M (2015) Laparoscopic parenchymal-sparing resections for nonperipheral liver lesions, the diamond technique: technical aspects, clinical outcomes, and oncologic efficiency. J Am Coll Surg 221:265-272

58. Kim JH (2019) Pure laparoscopic anatomical resection of the segment 8 dorsal area using the transparenchymal Glissonean approach (video). Surg Oncol 31:99-100

59. Ratti F, Cipriani F, Ariotti R, Gagliano A, Paganelli M, Catena M, Aldrighetti L (2016) Safety and feasibility of laparoscopic liver resection with associated lymphadenectomy for intrahepatic cholangiocarcinoma: a propensity score-based case-matched analysis from a single institution. Surg Endosc 30:1999-2010
60. Wei F, Wang G, Ding J, Dou C, Yu T, Zhang C (2019) Is it time to consider laparoscopic hepatectomy for intrahepatic cholangiocarcinoma? A meta-analysis. J Gastrointest Surg

61. Martin SP, Drake J, Wach MM, Ruff S, Diggs LP, Wan JY, Brown ZJ, Ayabe RI, Glazer ES, Dickson PV, Davis JL, Deneve JL, Hernandez JM (2019) Laparoscopic approach to intrahepatic cholangiocarcinoma is associated with an exacerbation of inadequate nodal staging. Ann Surg Oncol 26:1851-1857

62. Filmann N, Walter D, Schadde E, Bruns C, Keck T, Lang H, Oldhafer K, Schlitt HJ, Schön MR, Herrmann E, Bechstein WO, Schnitzbauer AA (2019) Mortality after liver surgery in Germany. Br J Surg 106:1523-1529

63. Feng F, Cao X, Liu X, Qin J, Zhang S, Li Q, Liu J (2019) Laparoscopic resection for Bismuth type III and IV hilar cholangiocarcinoma: how to improve the radicality without direct palpation. J Surg Oncol 120:1379-1385

64. Ratti F, Fiorentini G, Cipriani F, Catena M, Paganelli M, Aldrighetti L (2020) Perihilar cholangiocarcinoma: are we ready to step towards minimally invasiveness? Updat Surg. https://doi org/10.1007/s13304-020-00752-3

65. Zhang Y, Dou C, Wu W, Liu J, Jin L, Hu Z, Zhang C (2019) Total laparoscopic versus open radical resection for hilar cholangiocarcinoma. Surg Endosc. https://doi.org/10.1007/s00464-019-07211-0

66. Li J, Zhao L, Zhang J, Li Z, Li A, Wei Y, Xu J (2017) Application of the laparoscopic technique in perihilar cholangiocarcinoma surgery. Int J Surg 44:104-109

67. Chang K, Gokcal F, Kudsi OY (2020) Robotic biliary surgery. Surg Clin North Am 100:283-302

68. Ruurda JP, van Dongen KW, Dries J, Borel Rinkes IHM, Broeders IAMJ (2003) Robot-assisted laparoscopic choledochojejunostomy. Surg Endosc 17:1937-1942

69. Broering DC, Elsheikh Y, Shagrani M, Abaalkhail F, Troisi RI (2018) Pure laparoscopic living donor left lateral sectionectomy in pediatric transplantation: a propensity score analysis on 220 consecutive patients. Liver Transpl 24:1019-1030

70. Gautier S, Monakhov A, Gallyamov E, Tsirulnikova O, Zagaynov E, Dzhanbekov T, Semash K, Khizroev K, Oleshkevich D, Chekletsova E (2018) Laparoscopic left lateral section procurement in living liver donors: a single center propensity score-matched study. Clin Transpl 32:e13374

71. Soubrane O, de Rougemont O, Kim K-H, Samstein B, Mamode N, Boillot O, Troisi RI, Scatton O, Cauchy F, Lee SG, Griesemer A, Ahmed Z, Clavien PA, Cherqui D (2015) Laparoscopic living donor left lateral Sectionectomy: a new standard practice for donor hepatectomy. Ann Surg 262:757-761 discussion 761-3

72. Broering DC, Berardi G, El Sheikh Y, Spagnoli A, Troisi RI (2020) Learning curve under proctorship of pure laparoscopic living donor left lateral sectionectomy for pediatric transplantation. Ann Surg 271:542-548

73. Han H-S, Cho JY, Kaneko H, Wakabayashi G, Okajima H, Uemoto S, Soubrane O, Yong CC, Chen CL, Cheung TT, Belli G, Kubo S, Wu YM, Chen KH, Troisi RI, Kwon CHD, Suh KS, Soin AS, Kim KH, Cherqui D (2018) Expert panel statement on laparoscopic living donor hepatectomy. Dig Surg 35:284-288

74. Soubrane O, Eguchi S, Uemoto S, Kwon CHD, Wakabayashi G, Han H-S et al (2020) Minimally invasive donor hepatectomy for adult living donor liver transplantation: an international, multiinstitutional evaluation of safety, efficacy and early outcomes. Ann Surg

75. Jeong JS, Wi W, Chung YJ, Kim JM, Choi G-S, Kwon CHD, Han S, Gwak MS, Kim GS, Ko JS (2020) Comparison of perioperative outcomes between pure laparoscopic surgery and open right hepatectomy in living donor hepatectomy: propensity score matching analysis. Sci Rep 10:5314

76. Suh KS, Hong SK, Lee KW, Yi NJ, Kim HS, Ahn SW, Yoon KC, Choi JY, Oh D, Kim H (2018) Pure laparoscopic living donor 
hepatectomy: focus on 55 donors undergoing right hepatectomy. Am J Transplant 18:434-443

77. Hong SK, Tan MY, Worakitti L, Lee J-M, Cho J-H, Yi N-J, Lee KW, Suh KS (2020) Pure laparoscopic versus open right hepatectomy in live liver donors: a propensity score-matched analysis. Ann Surg Publish Ahead of Print

78. Wabitsch S, Schöning W, Kästner A, Haber PK, Benzing C, Krenzien F et al (2020) A propensity-matched study of full laparoscopic versus hand-assisted minimal-invasive liver surgery. Surg Endosc

79. Wabitsch S, Schulz P, Fröschle F, Kästner A, Fehrenbach U, Benzing C et al (2020) Incidence of incisional hernia after laparoscopic liver resection. Surg Endosc

80. Chong EH, Choi SH (2019) Hybrid laparoscopic and robotic hepatopancreaticoduodenectomy for cholangiocarcinoma. J Gastrointest Surg 23:1947-1948

81. Wabitsch S, Kästner A, Haber PK, Feldbrügge L, Winklmann T, Werner S, Pratschke J, Schmelzle M (2019) Laparoscopic versus open hemihepatectomy-a cost analysis after propensity score matching. Langenbeck's Arch Surg 404:469-475

82. Abu Hilal M, Di Fabio F, Syed S, Wiltshire R, Dimovska E, Turner D et al (2013) Assessment of the financial implications for laparoscopic liver surgery: a single-centre UK cost analysis for minor and major hepatectomy. Surg Endosc 27:2542-2550

83. Cannon RM, Scoggins CR, Callender GG, Quillo A, McMasters KM, Martin RCG 2nd. (2013) Financial comparison of laparoscopic versus open hepatic resection using deviation-based cost modeling. Ann Surg Oncol 20:2887-2892

84. Halls MC, Alseidi A, Berardi G, Cipriani F, Van der Poel M, Davila D et al (2019) A comparison of the learning curves of laparoscopic liver surgeons in differing stages of the IDEAL paradigm of surgical innovation: standing on the shoulders of pioneers. Ann Surg 269:221-228

85. Tomassini F, Scuderi V, Colman R, Vivarelli M, Montalti R, Troisi RI (2016) The single surgeon learning curve of laparoscopic liver resection: a continuous evolving process through stepwise difficulties. Medicine 95:e5138

86. Rahbari NN, Elbers H, Koch M, Vogler P, Striebel F, Bruckner T, Mehrabi A, Schemmer P, Büchler MW, Weitz J (2014) Randomized clinical trial of stapler versus clamp-crushing transection in elective liver resection. Br J Surg 101:200-207

87. Schemmer P, Bruns H, Weitz J, Schmidt J, Büchler MW (2008) Liver transection using vascular stapler: a review. HPB. 10:249252

88. Cosic L, Ma R, Churilov L, Debono D, Nikfarjam M, Christophi C et al (2019) The financial impact of postoperative complications following liver resection. Medicine 98:e16054

89. Wakabayashi G, Tanabe M (2020) ILLS 2019 and the development of laparoscopic liver resection in Japan. J Hepatobiliary Pancreat Sci. 27:1-2

90. Daskalaki D, Gonzalez-Heredia R, Brown M, Bianco FM, Tzvetanov I, Davis M, Kim J, Benedetti E, Giulianotti PC (2017) Financial impact of the robotic approach in liver surgery: a comparative study of clinical outcomes and costs between the robotic and open technique in a single institution. J Laparoendosc Adv Surg Tech A. 27:375-382

Publisher's note Springer Nature remains neutral with regard to jurisdictional claims in published maps and institutional affiliations. 